\title{
Surgical outcomes of pediatric spinal cord astrocytomas: systematic review and meta-analysis
}

\author{
Tej D. Azad, MS, ${ }^{1}$ Arjun V. Pendharkar, MD, ${ }^{1}$ James Pan, BS, ${ }^{1}$ Yuhao Huang, BS, ${ }^{1}$ Amy Li, BA, ${ }^{1}$ \\ Rogelio Esparza, BA, ${ }^{1}$ Swapnil Mehta, BA, ${ }^{1}$ lan D. Connolly, MS, ${ }^{1}$ Anand Veeravagu, MD, ${ }^{1}$ \\ Cynthia J. Campen, MD, MS, ${ }^{2}$ Samuel H. Cheshier, MD, PhD, ${ }^{1}$ Michael S. B. Edwards, MD, ${ }^{1}$ \\ Paul G. Fisher, MD, ${ }^{2}$ and Gerald A. Grant, MD'
}

Departments of ${ }^{1}$ Neurosurgery and ${ }^{2}$ Neurology, Stanford University School of Medicine, Stanford, California

\begin{abstract}
OBJECTIVE Pediatric spinal astrocytomas are rare spinal lesions that pose unique management challenges. Therapeutic options include gross-total resection (GTR), subtotal resection (STR), and adjuvant chemotherapy or radiation therapy. With no randomized controlled trials, the optimal management approach for children with spinal astrocytomas remains unclear. The aim of this study was to conduct a systematic review and meta-analysis on pediatric spinal astrocytomas.
\end{abstract}

METHODS The authors performed a systematic review of the PubMed/MEDLINE electronic database to investigate the impact of histological grade and extent of resection on overall survival among patients with spinal cord astrocytomas. They retained publications in which the majority of reported cases included astrocytoma histology.

RESULTS Twenty-nine previously published studies met the eligibility criteria, totaling 578 patients with spinal cord astrocytomas. The spinal level of intramedullary spinal cord tumors was predominantly cervical (53.8\%), followed by thoracic (40.8\%). Overall, resection was more common than biopsy, and GTR was slightly more commonly achieved than STR (39.7\% vs 37.0\%). The reported rates of GTR and STR rose markedly from 1984 to 2015 . Patients with high-grade astrocytomas had markedly worse 5-year overall survival than patients with low-grade tumors. Patients receiving GTR may have better 5 -year overall survival than those receiving STR.

CONCLUSIONS The authors describe trends in the management of pediatric spinal cord astrocytomas and suggest a benefit of GTR over STR for 5 -year overall survival.

https://thejns.org/doi/abs/10.3171/2018.4.PEDS17587

KEYWORDS extent of resection; gross-total resection; intramedullary spinal cord tumor; astrocytoma; spine

I NTRAMEDULLARY spinal cord tumors (IMSCTs) are rare lesions, with 100-200 new cases reported annually within the United States. ${ }^{17}$ The low incidence of these tumors has limited the development of evidencebased management strategies. ${ }^{5,19}$ Astrocytoma is the most common pediatric IMSCT and thus is the focus of this paper. ${ }^{1,15,16,23}$ Children with spinal cord astrocytoma often present several months after the onset of symptoms, ${ }^{8}$ with the degree of preoperative neurological function at diagnosis correlating with worse postoperative outcomes. ${ }^{6,721}$,
27,35 At clinical presentation, the most commonly reported symptoms are pain, motor deficits, frequent falls, sensory symptoms, and sphincter dysfunction. 1,8,27,28

Surgical management of spinal cord astrocytomas can vary from biopsy to attempted gross-total resection (GTR). The extent of resection is influenced by age, tumor size and location, degree of dissemination, patient preference, and quality of life. In contrast to spinal ependymomas, astrocytomas often lack a clear surgical plane with which to attempt GTR. Use of adjuvant radio- or chemotherapy var-

ABBREVIATIONS GBM = glioblastoma; GTR = gross-total resection; IMSCT = intramedullary spinal cord tumor; OS = overall survival; SEER = Surveillance, Epidemiology, and End Results; STR = subtotal resection.

SUBMITTED October 23, 2017. ACCEPTED April 17, 2018.

INCLUDE WHEN CITING Published online July 20, 2018; DOI: 10.3171/2018.4.PEDS17587. 


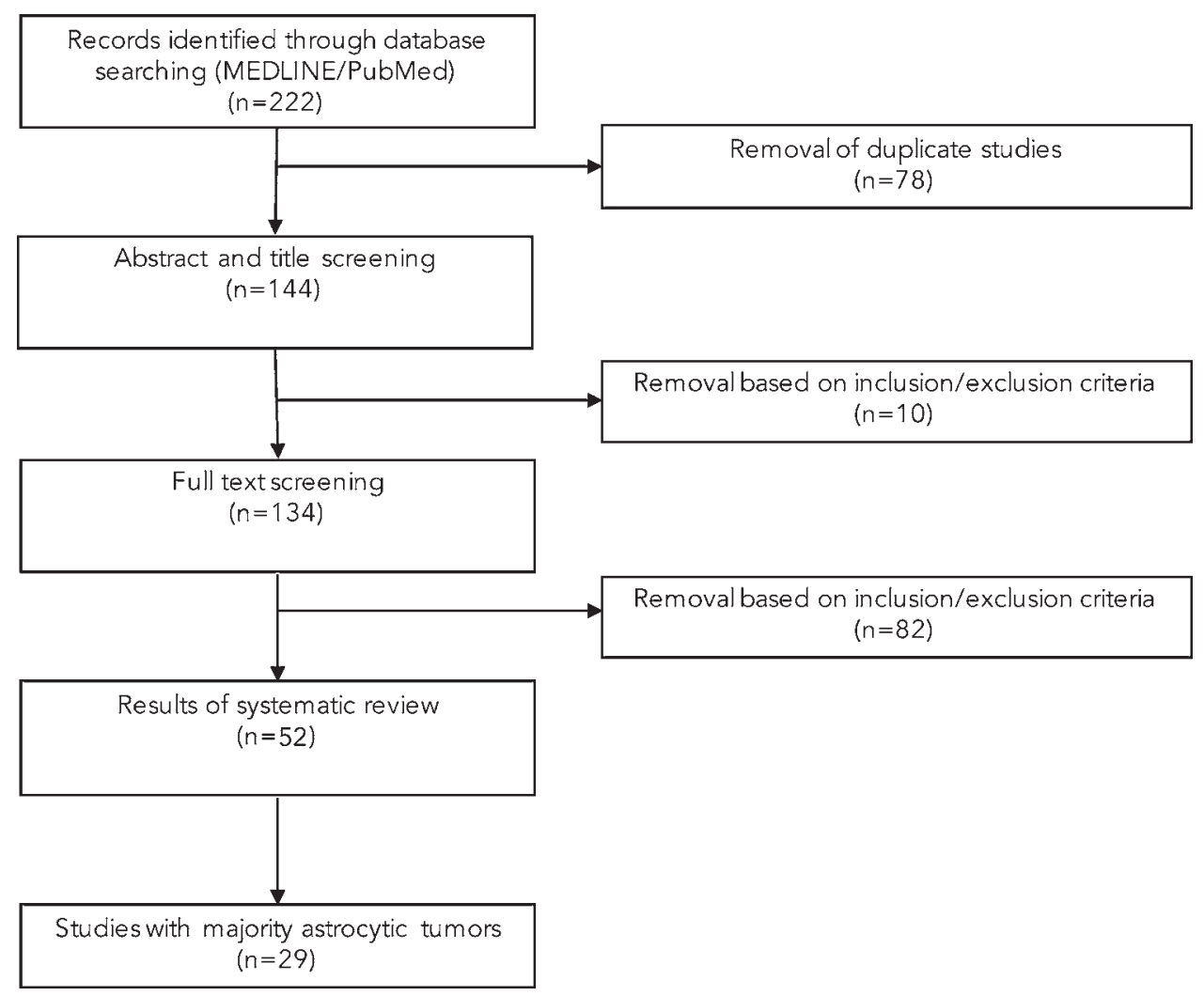

FIG. 1. PRISMA diagram for systematic review.

ies by institution. ${ }^{5}$ While there has been no definitive study demonstrating improved survival outcomes with more aggressive extent of resection in the management of pediatric spinal cord astrocytomas, a recent population-level study of the Surveillance, Epidemiology, and End Results (SEER) database reported a survival benefit for both subtotal resection (STR) and GTR in pediatric patients with spinal cord astrocytomas. ${ }^{24}$

In the current study, we systematically reviewed the literature on pediatric spinal cord astrocytomas. We describe management trends and synthesize data on the impact of histological grade and extent of resection on overall survival (OS).

\section{Methods}

\section{Search Strategy and Study Selection}

The present study was conducted in accordance with the PRISMA (Preferred Reporting Items for Systematic Reviews and Meta-Analyses) guidelines (Fig. 1). The PubMed/MEDLINE electronic database and bibliographies of relevant articles were systematically searched for English-language articles with no timeframe restrictions through June 2016. The following terms in various combinations were used: spine, spinal, intramedullary, tumor, astrocytoma, glioma, glioblastoma, child, children, and pediatric. Three authors independently performed the literature searches. Discrepancies among reviewers were resolved through discussion.

Studies were included if the majority of patients in the study had a confirmed diagnosis of pediatric spinal cord astrocytomas, received operative management, and belonged to the pediatric population. Exclusion criteria included review articles, case reports, fewer than 3 patients meeting inclusion criteria, studies in which pediatric and adult natural history and outcome variables could not be distinguished, and studies in which intramedullary location of the tumor could not be confirmed in the report.

\section{Data Extraction}

From the 29 published studies, we extracted the study type, sample size, patient demographics, extent of resection, adjuvant therapy, and outcome measures. We collected data on the following outcomes: OS and recurrence rate. These data were either directly taken from the studies when reported or calculated from raw data published in the paper.

\section{Data Synthesis}

Using data from studies that enabled extraction of data on astrocytomas only, we evaluated survival outcomes., ${ }^{1,2}$, 5,7,9-15,17,18,21,22,25-27,29-34,36,37,39-41 We extracted individual patient data to calculate the 5-year OS stratified by histological grade and extent of resection using the Kaplan-Meier estimator. OS and the 95\% CI were plotted for each study using forest plots. Heterogeneity among studies was assessed using the Q-test. The $\mathrm{I}^{2}$ statistic, which is the percentage total variation, was reported, with $\mathrm{I}^{2}>50 \%$ used 

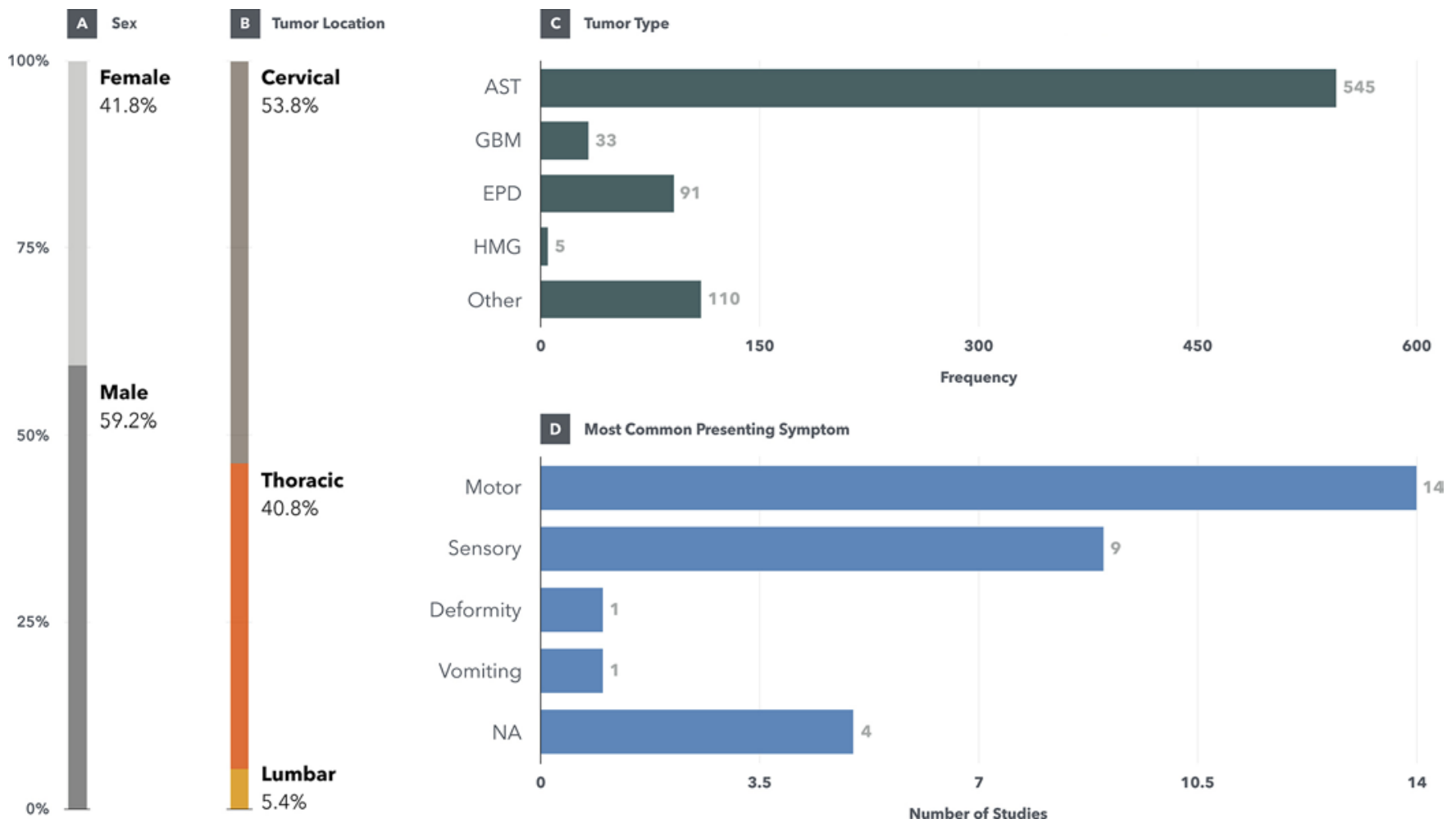

FIG. 2. Pediatric spinal astrocytoma demographics with regard to sex (A), tumor location (B), tumor histology (C), and presenting symptoms (D). Astrocytoma (AST) includes grade I-III astrocytomas. GBMs are reported separately, as many studies reported findings for spinal GBM distinct from other spinal astrocytomas. EPD = ependymoma; HMG = hemangioma; $\mathrm{NA}=$ not available. Figure is available in color online only.

as the threshold for significant study heterogeneity. As hazard ratios were not computed, bias was not assessed.

\section{Statistical Analysis}

Descriptive statistics are presented as mean and standard deviation or median and interquartile range. All statistical analyses were performed using the $R$ statistical computing language.

\section{Results}

\section{Results of Systematic Review}

Eligibility criteria were met by 29 previously published studies (Fig. 1), totaling 578 patients with spinal astrocytomas. The median cohort size of the studies was 20 (IQR 10-29), with the smallest and largest studies enrolling 3 and 164 patients, respectively. The overall quality of eligible studies was found to be either low $(36 \%)$ or very low (64\%), utilizing the GRADE (Grade of Recommendations Assessment, Development and Evaluation) criteria. ${ }^{3}$

\section{Demographics of Patients With Pediatric Spinal Cord Astrocytomas}

The mean age at diagnosis in our study was 8.6 years (SD 2.2), while the mean age at surgery was 10.1 years (SD 2.6). Males were represented more than females, with a male-to-female ratio of 1.45:1 (Fig. 2A). The spinal level of IMSCTs was predominantly cervical (53.8\%), followed by thoracic ( $40.8 \%$; Fig. 2B). While this report focused on spinal astrocytomas, several of the studies in the systematic review also included other pediatric IMSCTs. Nonglioblastoma (GBM) astrocytomas (545 patients, $69.5 \%$ of all tumors) represented most tumors, followed by other tumors (e.g., ganglioglioma) $(110,14.0 \%)$, ependymoma (91, $11.6 \%)$, GBM $(33,4.2 \%)$, and hemangioblastoma $(5,0.6 \%$; Fig. 2C). The most common presenting symptoms were motor (14, 56\% of studies) and sensory (9,36\% of studies) deficits. Other presenting symptoms included deformity $(1,4 \%)$ and vomiting $(1,4 \%$; Fig. 2D). Four studies (16\%) did not report presenting symptoms.

\section{Management Trends of Patients With Pediatric Spinal Cord Astrocytomas}

Overall, resection was more often performed than biopsy alone (76.7\% vs $23.3 \%$ ), and more patients received GTR than STR (39.7\% vs 37.0\%). To better understand current trends in management of spinal astrocytomas, we evaluated the rates of different treatment modalities (GTR, STR, adjuvant radiotherapy, and adjuvant chemotherapy) from 1984 to 2015 (Fig. 3). Over this time, the average rate of reported GTR rose from less than 25\% (prior to 1990) to roughly 50\% (in 2016), with rates of STR rising in parallel. We further observed a marked increase in rates of adjuvant chemotherapy and a decrease in the percentage of patients receiving adjuvant radiotherapy. We further ob- 

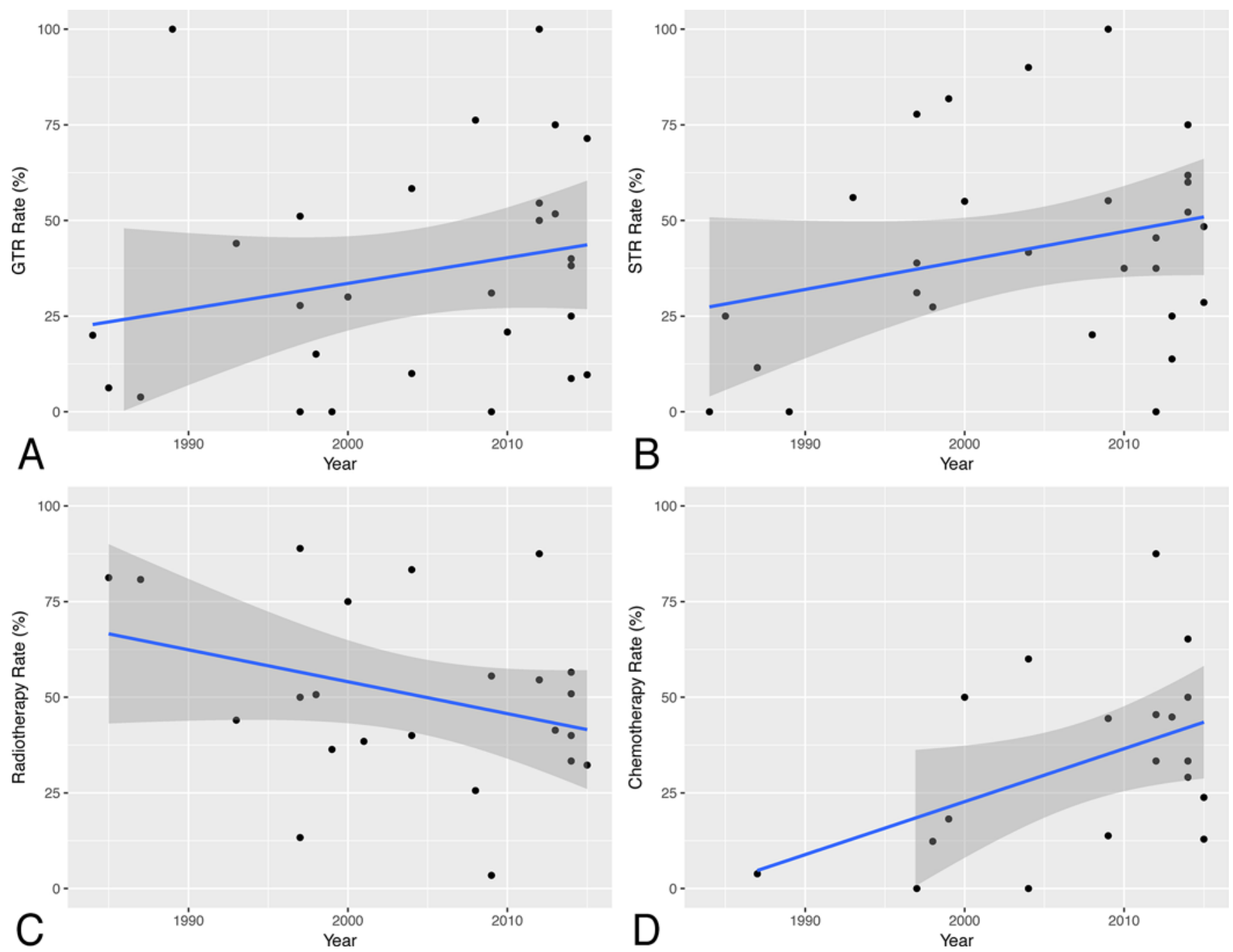

FIG. 3. Trends in the management of patients with pediatric spinal astrocytomas, 1984-2015, for GTR (A), STR (B), radiotherapy (C), and chemotherapy (D). Figure is available in color online only.

served an overall decrease in reported rates of recurrence over time (Fig. 4).

\section{Influence of Extent of Resection and Histological Grade on 5 -Year OS}

To investigate the influence of histological grade and extent of resection on survival among patients with pediatric spinal astrocytoma, we selected studies that reported either individual patient data or composite outcomes in series that included astrocytomas only. Four studies reported survival outcomes for patients receiving GTR, with 5-year OS ranging from 0.9 to 1.0 (Fig. 5A). Among the 5 studies that provided data for patients receiving STR, 5-year OS ranged from 0.5 to 1.0 (Fig. 5B). The study with the largest sample size, Bouffet et al. $(\mathrm{n}=53)$, reported a 5-year OS of 0.9?

Seven studies reported outcomes for patients with lowgrade astrocytomas, with 5-year OS ranging from 0.8 to 1.0 (Fig. 5C). Among the 5 studies reporting outcomes for high-grade astrocytomas, 5-year OS ranged from 0.0 to
0.71 (Fig. 5D), with the largest series reporting a 5-year OS of 0.33 .

\section{Discussion}

In this study, we conducted a systematic review of the literature to better understand the demographics and management trends of patients with spinal cord astrocytoma. We collected data on 578 patients with pediatric spinal astrocytomas from a total of 29 published reports and sought to evaluate the impact of histological grade and extent of resection on overall survival, efficacy of adjuvant treatments and resection on recurrence, and mortality within the pediatric age group. Analysis of all studies meeting inclusion criteria demonstrated a preponderance of retrospective single-institution studies and an absence of prospective studies or randomized trials. These findings are consistent with prior literature reviews and reflect the rarity of spinal astrocytomas and the difficulty in designing neurosurgical randomized trials. ${ }^{4}$ In an effort to overcome these challenges, several authors have called for 


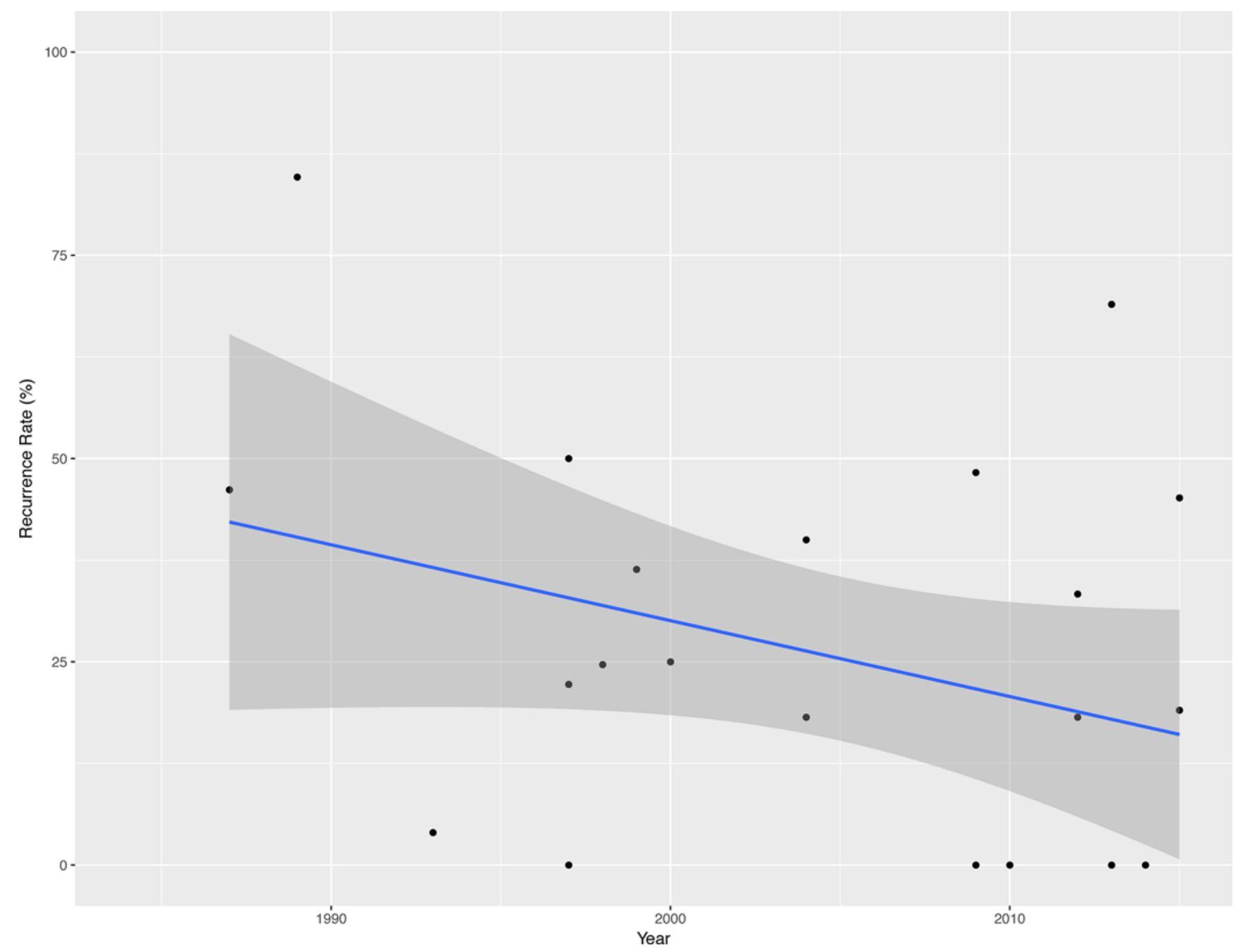

FIG. 4. Decrease in overall recurrence rates, 1984-2016. Figure is available in color online only.

multiinstitutional studies. ${ }^{20,42}$ However, with an incidence rate of 100-200 new cases per year in the United States, we agree with Scheinemann et al. that an international registry of patient data may be the best means to evaluate, refine, and expand on existing treatment approaches in the literature. ${ }^{36}$

We found a male preponderance among the patients in this review, which appears to be consistent with previous reports. ${ }^{15,38}$ We also found that among individuals studied, patients first presented to care near the middle of childhood (mean 8.6 years) and underwent surgery only slightly later (mean 10.1 years old). The vast majority of tumors were located in the cervical or thoracic spine, and the most common presenting symptoms were motor. Consistent with previous reports ${ }^{5,7}$ and a recent population-level study, ${ }^{24}$ we found a marked impact of histological grade on survival outcomes. We also observed that patients receiving GTR might have improved survival outcomes, compared with patients receiving STR. However, this finding must be interpreted with caution, as we were unable to control for tumor grade in this analysis. Low-grade astrocytomas, which have definitively better survival outcomes, may be more amenable to GTR. An important companion finding to our results is that both GTR and STR appear to be protective for survival when histological grade was accounted for in a recent SEER study of pediatric spinal astrocytomas. ${ }^{24}$

This study is not without limitations. All studies we identified were retrospective and thus may be biased with regard to patient selection and recall. Moreover, hazard ratios for OS and progression-free survival were largely unavailable for synthesis. Thus, we were limited in our ability to explicitly assess bias. At the review level, a potential limitation is incomplete retrieval of studies, a limitation of all systematic reviews. In this review of spinal astrocytomas, a particular concern is the overall low quality of the constituent studies. The rare nature of these lesions has, to date, precluded studies that are prospective and/or randomized, directly limiting the GRADE scores of these studies.

\section{Conclusions}

Overall, our results appear to be consistent with literature advocating that more aggressive resection may be 


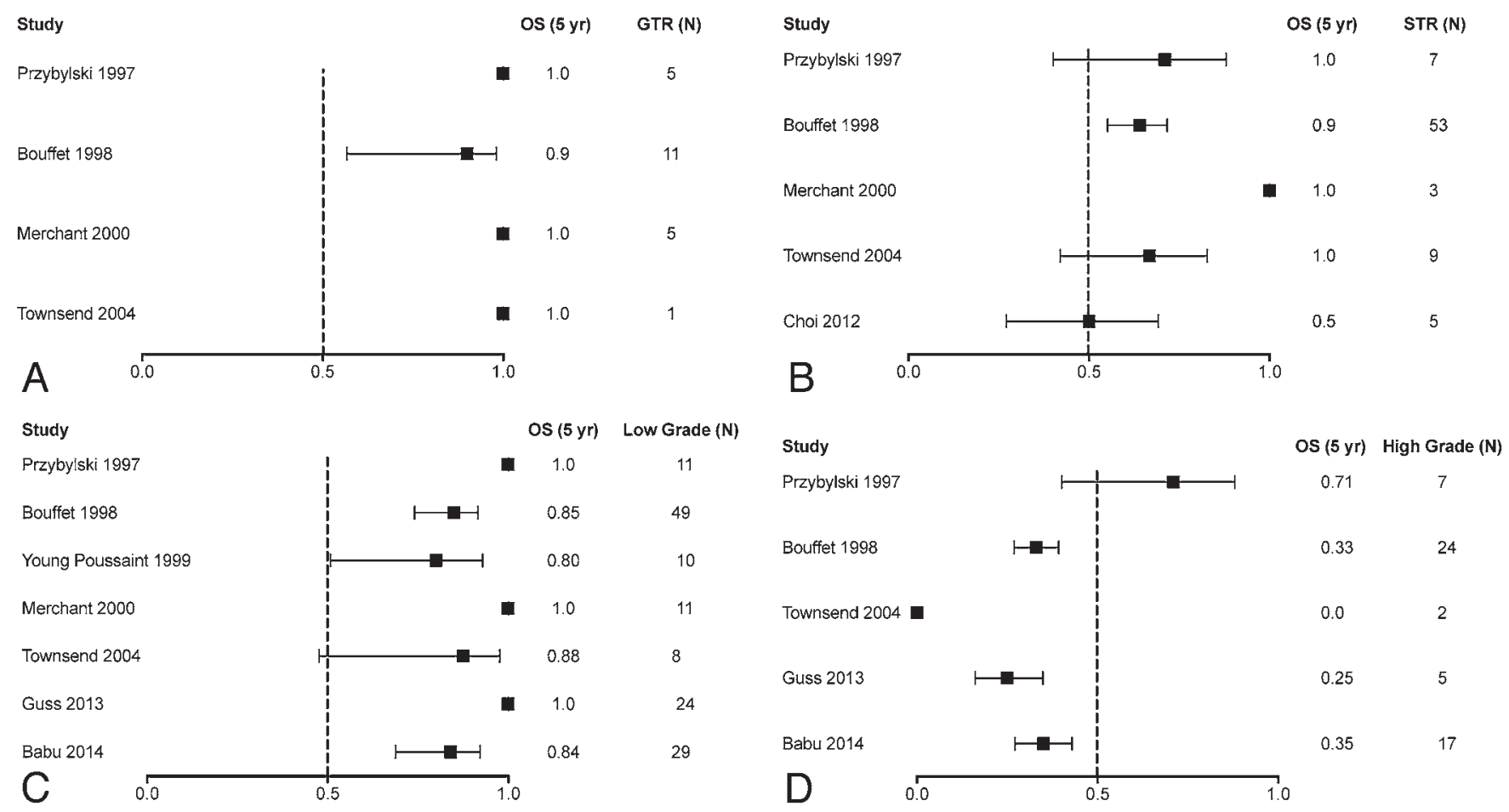

FIG. 5. Forest plots of 5-year OS stratified by GTR (A), STR (B), low-grade histology (C), and high-grade histology (D).

beneficial in the management of pediatric spinal astrocytoma. Given the rare nature of these lesions, synthesis across studies enables analysis of a larger cohort, an advantage of our study. Further studies, possibly through collaborative patient registries, are required to elucidate the optimal treatment strategy for children with spinal astrocytoma.

\section{References}

1. Ahmed R, Menezes AH, Awe OO, Torner JC: Long-term disease and neurological outcomes in patients with pediatric intramedullary spinal cord tumors. J Neurosurg Pediatr 13:600-612, 2014

2. Ardeshiri A, Chen B, Hütter BO, Oezkan N, Wanke I, Sure U, et al: Intramedullary spinal cord astrocytomas: the influence of localization and tumor extension on resectability and functional outcome. Acta Neurochir (Wien) 155:1203-1207, 2013

3. Atkins D, Best D, Briss PA, Eccles M, Falck-Ytter Y, Flottorp $\mathrm{S}$, et al: Grading quality of evidence and strength of recommendations. BMJ 328:1490, 2004

4. Azad TD, Veeravagu A, Mittal V, Esparza R, Johnson E, Ioannidis JPA, et al: Neurosurgical randomized controlled trials-distance travelled. Neurosurgery 82:604-612, 2018

5. Babu R, Karikari IO, Owens TR, Bagley CA: Spinal cord astrocytomas: a modern 20-year experience at a single institution. Spine (Phila Pa 1976) 39:533-540, 2014

6. Bansal S, Suri A, Borkar SA, Kale SS, Singh M, Mahapatra AK: Management of intramedullary tumors in children: analysis of 82 operated cases. Childs Nerv Syst 28:2063-2069, 2012

7. Bouffet E, Pierre-Kahn A, Marchal JC, Jouvet A, Kalifa C, Choux M, et al: Prognostic factors in pediatric spinal cord astrocytoma. Cancer 83:2391-2399, 1998

8. Chatterjee $\mathrm{S}$, Chatterjee U: Intramedullary tumors in children. J Pediatr Neurosci 6 (Suppl 1):S86-S90, 2011

9. Cheng JS, Ivan ME, Stapleton CJ, Quinones-Hinojosa A,
Gupta N, Auguste KI: Intraoperative changes in transcranial motor evoked potentials and somatosensory evoked potentials predicting outcome in children with intramedullary spinal cord tumors. J Neurosurg Pediatr 13:591-599, 2014

10. Choi GH, Oh JK, Kim TY, You NK, Lee HS, Yoon DH, et al: The clinical features and surgical outcomes of pediatric patients with primary spinal cord tumor. Childs Nerv Syst 28:897-904, 2012

11. Citron N, Edgar MA, Sheehy J, Thomas DG: Intramedullary spinal cord tumours presenting as scoliosis. J Bone Joint Surg Br 66:513-517, 1984

12. Cohen AR, Wisoff JH, Allen JC, Epstein F: Malignant astrocytomas of the spinal cord. J Neurosurg 70:50-54, 1989

13. Di Maio S, Gul SM, Cochrane DD, Hendson G, Sargent MA, Steinbok P: Clinical, radiologic and pathologic features and outcome following surgery for cervicomedullary gliomas in children. Childs Nerv Syst 25:1401-1410, 2009

14. Ebner FH, Schittenhelm J, Roser F, Scheel-Walter H, Tatagiba M, Schuhmann MU: Management of holocord pilocytic astrocytomas in children and adolescents: an update. Pediatr Neurosurg 48:133-140, 2012

15. Gepp RDA, Couto JM, Silva MD, Silva RT, Neri EA: Intramedullary tumors in children: analysis of 24 operated cases. Arq Neuropsiquiatr 68:396-399, 2010

16. Goh KY, Velasquez L, Epstein FJ: Pediatric intramedullary spinal cord tumors: is surgery alone enough? Pediatr Neurosurg 27:34-39, 1997

17. Guss ZD, Moningi S, Jallo GI, Cohen KJ, Wharam MD, Terezakis SA: Management of pediatric spinal cord astrocytomas: outcomes with adjuvant radiation. Int J Radiat Oncol Biol Phys 85:1307-1311, 2013

18. Hardison HH, Packer RJ, Rorke LB, Schut L, Sutton LN, Bruce DA: Outcome of children with primary intramedullary spinal cord tumors. Childs Nerv Syst 3:89-92, 1987

19. Harrop JS, Ganju A, Groff M, Bilsky M: Primary intramedullary tumors of the spinal cord. Spine (Phila Pa 1976) 34 (22 Suppl):S69-S77, 2009 
20. Hassall TE, Mitchell AE, Ashley DM: Carboplatin chemotherapy for progressive intramedullary spinal cord low-grade gliomas in children: three case studies and a review of the literature. Neuro Oncol 3:251-257, 2001

21. Innocenzi G, Raco A, Cantore G, Raimondi AJ: Intramedullary astrocytomas and ependymomas in the pediatric age group: a retrospective study. Childs Nerv Syst 12:776-780, 1996

22. Kumar R, Singh V: Intramedullary mass lesion of the spinal cord in children of a developing milieu. Pediatr Neurosurg 40:16-22, 2004

23. Kushel IV, Belova ID: [Epidemiology of pediatric intramedullary spinal cord tumors.] Zh Vopr Neirokhir Im N N Burdenko 78:37-42, 2014 (Russian)

24. Luksik AS, Garzon-Muvdi T, Yang W, Huang J, Jallo GI: Pediatric spinal cord astrocytomas: a retrospective study of 348 patients from the SEER database. J Neurosurg Pediatr 19:711-719, 2017

25. Lunardi P, Licastro G, Missori P, Ferrante L, Fortuna A: Management of intramedullary tumours in children. Acta Neurochir (Wien) 120:59-65, 1993

26. McAbee JH, Modica J, Thompson CJ, Broniscer A, Orr B, Choudhri AF, et al: Cervicomedullary tumors in children. J Neurosurg Pediatr 16:357-366, 2015

27. McGirt MJ, Chaichana KL, Atiba A, Attenello F, Yao KC, Jallo GI: Resection of intramedullary spinal cord tumors in children: assessment of long-term motor and sensory deficits. J Neurosurg Pediatr 1:63-67, 2008

28. McGirt MJ, Chaichana KL, Atiba A, Bydon A, Witham TF, Yao KC, et al: Incidence of spinal deformity after resection of intramedullary spinal cord tumors in children who underwent laminectomy compared with laminoplasty. J Neurosurg Pediatr 1:57-62, 2008

29. Merchant TE, Kiehna EN, Thompson SJ, Heideman R, Sanford RA, Kun LE: Pediatric low-grade and ependymal spinal cord tumors. Pediatr Neurosurg 32:30-36, 2000

30. Mottl H, Koutecky J: Treatment of spinal cord tumors in children. Med Pediatr Oncol 29:293-295, 1997

31. Ononiwu C, Mehta V, Bettegowda C, Jallo G: Pediatric spinal glioblastoma multiforme: current treatment strategies and possible predictors of survival. Childs Nerv Syst 28:715720, 2012

32. Özkan N, Jabbarli R, Wrede KH, Sariaslan Z, Stein KP, Dammann P, et al: Surgical management of intradural spinal cord tumors in children and young adults: a single-center experience with 50 patients. Surg Neurol Int 6 (Suppl 27):S661-S667, 2015

33. Przybylski GJ, Albright AL, Martinez AJ: Spinal cord astrocytomas: long-term results comparing treatments in children. Childs Nerv Syst 13:375-382, 1997

34. Reimer R, Onofrio BM: Astrocytomas of the spinal cord in children and adolescents. J Neurosurg 63:669-675, 1985

35. Sahu RK, Das KK, Bhaisora KS, Singh AK, Mehrotra A, Srivastava AK, et al: Pediatric intramedullary spinal cord lesions: pathological spectrum and outcome of surgery. J Pediatr Neurosci 10:214-221, 2015

36. Scheinemann K, Bartels U, Huang A, Hawkins C, Kulkarni AV, Bouffet E, et al: Survival and functional outcome of childhood spinal cord low-grade gliomas. Clinical article. J Neurosurg Pediatr 4:254-261, 2009

37. Schneider C, Hidalgo ET, Schmitt-Mechelke T, Kothbauer KF: Quality of life after surgical treatment of primary intramedullary spinal cord tumors in children. J Neurosurg Pediatr 13:170-177, 2014

38. Sonneland PR, Scheithauer BW, Onofrio BM: Myxopapillary ependymoma. A clinicopathologic and immunocytochemical study of 77 cases. Cancer 56:883-893, 1985

39. Townsend N, Handler M, Fleitz J, Foreman N: Intramedullary spinal cord astrocytomas in children. Pediatr Blood Cancer 43:629-632, 2004

40. Yeh JS, Sgouros S, Walsh AR, Hockley AD: Spinal sagittal malalignment following surgery for primary intramedullary tumours in children. Pediatr Neurosurg 35:318-324, 2001

41. Young Poussaint T, Yousuf N, Barnes PD, Anthony DC, Zurakowski D, Scott RM, et al: Cervicomedullary astrocytomas of childhood: clinical and imaging follow-up. Pediatr Radiol 29:662-668, 1999

42. Zou Y, Bai HX, Wang Z, Jiang Y, Yang L: Radiation therapy after subtotal resection of pediatric grade II/III spinal ependymomas: what is the evidence? Childs Nerv Syst 31:10211022,2015

\section{Disclosures}

The authors report no conflict of interest concerning the materials or methods used in this study or the findings specified in this paper.

\section{Author Contributions}

Conception and design: Grant, Azad, Pendharkar, Veeravagu, Cheshier. Acquisition of data: Azad, Pan, Huang, Li, Esparza, Mehta, Connolly, Campen, Cheshier, Edwards, Fisher. Analysis and interpretation of data: Grant, Azad, Pendharkar, Pan, Huang, Li, Esparza, Mehta, Connolly, Campen, Cheshier, Edwards, Fisher. Drafting the article: Grant, Azad, Pendharkar, Pan, Huang, Li, Esparza, Mehta, Connolly, Veeravagu, Campen, Fisher. Critically revising the article: Azad, Pendharkar, Veeravagu, Campen, Cheshier, Edwards, Fisher. Reviewed submitted version of manuscript: Grant, Azad, Veeravagu, Campen, Edwards. Approved the final version of the manuscript on behalf of all authors: Azad. Statistical analysis: Azad, Huang. Administrative/technical/material support: Grant.

\section{Correspondence}

Gerald A. Grant: Stanford University School of Medicine, Stanford,CA.ggrant2@stanford.edu. 